\title{
The Metamorphosis of Systems Engineering through the evolution of today's standards
}

\author{
Dr. David Ward \\ Systems Engineering Manager \\ Flex Design S.r.l. \\ Milan, Italy \\ david.ward@flex.com \\ Brendan Patrick Sullivan \\ Politecnico di Milano \\ Department of Management and Industrial Engineering \\ Milan, Italy \\ brendan.sullivan@polimi.it
}

\author{
Dr. Monica Rossi \\ Associate Professor \\ Politecnico di Milano \\ Department of Management and Industrial Engineering \\ Milan, Italy \\ monica.rossi@polimi.it \\ Harsha Vardhan Pichika \\ M.Sc. in Management Engineering \\ Politecnico di Milano \\ Milan, Italy \\ harshavardhan.pichika@mail.polimi.it
}

\begin{abstract}
Within aggressive dynamic markets, products today are becoming more complex as they manage rapid technology advancements, shorter system life cycles, organizational changes, and mounting regulatory pressures. Necessitating organizations to respond on several fronts in order to effectively manage the application and adoption of cutting-edge technical standards and systems engineering. These challenges have been identified as forces that are shaping modern industries and defining the systems engineering roadmap. This paper sets out to describe and document this system engineering metamorphosis by leveraging its heritage, as well as past and present standards. It discusses the forces behind this evolution and introduces key SE standards and materials such as ISO/IEC/IEEE 15288 (life cycle processes), ISO/IEC/IEEE 29148 (requirements processes) and the INCOSE Systems Engineering handbook which explain the processes related to systems engineering. These specific standards provide an elaboration of processes that benefit enterprises dealing with products and services of high complexity. This paper also explains the key concepts and tools such as the 'tailoring' of processes through a framework and utilization of the input-process-output (IPO) diagram. By providing a snapshot of current challenges in society this paper also aims to provide insight of what can be expected for SE centred and steered design typically encountered in high-tech integrators/manufacturers. In conclusion, organizations, including those in the biomedical and healthcare sectors, that effectively leverage SE standards and the INCOSE SE Handbook can be better positioned to develop safe(r) and more effective products once these approaches become common practice.
\end{abstract}

Keywords - Systems engineering, Systems Engineering standards, ISO/IEC/IEEE 15288, ISO/IEC/IEEE 29148, INCOSE Systems Engineering handbook, Systems Engineering processes, Tailoring processes. Systems engineering in the medical industry.

\section{INTRODUCTION}

It has been said that systems engineering (SE) is a forgone conclusion when developing complex systems, meaning that there is an underlying conviction across the industry that it is already part and parcel of the daily product or service development/deployment engineering process. In some other cases, SE is simply classified as a rebranding exercise of Engineering and Design. However, in reality there are sectors such as the Military and Aerospace that are considerably ahead in their SE journey, when compared, for example, to that of the medical industry [1].

There are many reasons why SE development and deployment can be seen as lagging and sporadic including, increased design complexity, technology advancement, shorter system life cycles, rapid organizational changes, mounting regulatory pressure and aggressive market dynamics are dominant. Perhaps even more challenging are other elements that are often neglected or where awareness is limited or even non-existent [2], such as:

1) Ownership and Liability: For example, if a system is successful or fails who should reap the rewards or burden the blame; e.g. identificaiton of the system stakeholders.

2) A new and blurred legislative landscape: In which there is a shift from the physical to the meta-physical; e.g. from maritime territorial to cyberspace law, from national to regional-international law [3].

3) Combined Societal-Technological advancement: With the introduction of concepts like 'Innovation to Zero', self-sufficiency and Smart cities etc. there has been an acceleration in the conflation of societal and technological trends.

4) Convergence and Integration of Natural and Manmade Systems: Examples being body implants, materials, human-centred systems etc. [4].

5) Compressed product/service development processes: For example, engineering design processes combined with very diverse and non-linear development models to develop innovative products while learning on-the-fly.

These elements represent some of the rules when considering the SE playing space, its metamorphosis and standardization.

Consequently, SE standards and their application are crucial for today's systems-centred projects, as they employ 
formal and universal terminology and procedures that are based on rigorous systems thinking and experience. Together, these clarify and fortify the above processes and prevent project teams from reinventing the wheel or inventing a 'square' version. Moreover, formal and informal processes must be balanced in their creation and adoption to yield the efficiencies made possible through standardization and the efficiency and effectiveness gained by applying SE processes. Since no two projects are identical, no two processes or applications can be identical either and some adaptability i.e. tailoring, is necessary [5].

Organizations must therefore develop tailorable guidelines and actions that are broad enough to span the range of projects within their portfolio otherwise projects will suffer [6]. Successful tailoring results in modified processes that facilitate the achievement of the goals of SE while breeding and deploying a SE school-of-thought throughout the project team and organization [7].

In general, when discussing SE development and deployment, including tailoring, the focus is on 'internal' forces [8] such as organisational constraints. But tailoring also needs to contemplate 'external forces' as these also effect SE development and deployment such as regulatory, certification, buyer-supplier agreements and of course applicable standards.

\section{ORIGIN AND DEFINITION OF SYSTEMS ENGINEERING}

Even though SE dates to the early 1940s' at Bell laboratories it is often associated with the effects of World War II, and boom of industrial expanse in 1950s and 1960s [9]. Several textbooks were published in this period to testify the birth of systems engineering as a distinct discipline [10]. Systems engineering evolved as a new branch of engineering and soon stood alone from other classical disciplines such as mechanical, electrical, civil engineering. It would be joined later in the late $60 \mathrm{~s}$ by software engineering that also responded to difficulties in governing complex systems [11]. The recognition of systems engineering as a unique discipline evolved as a natural outcome to the rapid growth of technology, and its application, most notably in major military, defence, space and relevant commercial contexts. After its inception in the second half of the last century it bridged into other industries such as energy and transport and more recently, in the new century also medical. Its success lies in its inter-disciplinary approach and engineering management of complex systems including systems-ofsystems. It can therefore be both a separate discipline and a reference platform and guidance for other engineering disciplines.

Systems engineering has various definitions across different industries, authorities and standards. According to the INCOSE SE handbook, it is defined as, "an interdisciplinary approach and means to enable the realization of successful systems" [12]. It focuses on defining customer needs and required functionality early in the development cycle, documenting requirements, and then proceeding with design synthesis and system validation while considering the complete problem i.e. operations, cost and schedule, performance, training and support, test, manufacturing, and disposal. SE is now seen as a stand-alone discipline yet also integrated in other engineering fields and specialty groups. In this way SE forges a team effort forming a structured development process that advances from concept to production to operation. "SE considers both the business and the technical needs of the (project) customer with the goal of providing a quality product that meets the user needs" [13]. These definitions summarize the meaning of systems engineering today and is applicable to any kind of industry.

According to Kossiakoff, "Systems engineering bridges the traditional engineering disciplines. The diversity of the elements in a complex system requires different engineering disciplines to be involved in their design and development. For the system to perform correctly, each system element must function properly in combination with one or more other system elements. Implementation of these interrelated functions is dependent on a complex set of physical and functional interactions between separately designed elements. Thus, the various elements cannot be engineered independently of one another and then simply assembled to produce a working system" [10]. A function of systems engineering is to guide and govern the engineering of complex systems, irrespective of the industry of where it is applied.

The INCOSE handbook discusses the relationship of modern systems engineering to its origins by considering three basic factors respectively, 1. Advancing Technology: which provide opportunities for increasing system capabilities, but introduces development risks that require systems engineering management; 2. Competition: whose various forms require seeking superior system solutions through system level trade-offs among alternative approaches; 3. Specialization: which requires the partitioning of the system into building blocks corresponding to specific product types [10]. These factors are also reflected in relevant systems engineering standards.

\section{INCOSE SYSTEMS ENGINEERING HANDBOOK}

The INCOSE handbook further serves as a reference for organizations to help them transform the needs of their customers into meaningful and feasible requirements. It doesn't show specifically how to do this rather it introduces many different and diverse SE related tools such as IPO, AGILE, RVTM as well as providing common SE terminology. In addition five case studies (including medical) of complex systems are provided as discussion points in chapter 3 and illustrate how SE principles and practices can be applied. Such case studies provide practical evidence why SE is needed [12], [14].

The INCOSE SE handbook also acts as a reference for SE including standards, models, lifecycle stages, processes, and their inherent tools and methods. Therefore, it addresses the lifecycle models and SE processes that may or may not fully apply to a given organization/project. Most are accompanied by a recommendation or allowance to adapt them to the situation at hand [12]. Indeed, the handbook 
elaborates on process tailoring to ensure that the process under review meets the needs of the project and the stage of development of the system. Since engineering design is iterative and recursive throughout the lifecycle so is tailoring. The authors suggest that tailoring should have both feedback and feedforward mechanisms to maximise the performance and fulfilment of the project and incurred system requirements. In short, processes should be continually monitored and adapted to suit the needs of the project. In applying tools such as the IPO the authors found that three process tailoring circumstances are possible:

- No tailoring is needed so the process is left and used 'as is'. That said, it should be documented for future review.

- Tailoring is needed, and an agreement is summoned by the stakeholders who are or could be impacted.

- Process is tailorable but an assessment involving the stakeholders is first done before deciding to tailor.

SE can be applied to any size and type of system (product/service) and organization, although it is most suitable to complex scenarios. That said it shouldn't be applied blindly and will need a learning phase to maximize its benefits. In fact, the authors have found that simple systems can be tackled also directly by the design team without the involvement of specific SE competency providing they are systems thinkers in their own disciplines. In terms of the development and deployment of a SE competency in an organization the authors have found that this will take at least 3-5 years before benefits across the organization can be witnessed and is a more 8 to 10 year journey in the making. Clearly shorter-term paybacks are possible but most likely in single projects or parts of programs and/or limited stretches of the product development process (PDP).

An equally important aspect is the need to staff SE led projects adequately and consistently. As found by Honour (2013) if you under or over-staff (in terms of SE) a project it will cost more and/or take longer [12]. Similarly, assessments in combining PM and SE functions, or at least aligning them better, have also been discussed [15].

\section{EVOLUTION OF SYSTEMS ENGINEERING STANDARDS}

There are many standards and models that exist (and have existed) that describe so-called SE processes as well as "best practices" in striving for a SE design approach. In 1969, the first SE standard was published to establish systems engineering management methods [14], [16]. The goal was to provide a set of criteria to serve as a guide to contractors preparing SE proposals and validating the contractor's systems engineering management capability in the military and defence sector. It then went through several iterations before ending up as 499b in 1994, after which it was split into two branches EIA/IS 632 and IEEE 1220. The ANSI/EIA/IS 632, published in 1999 was titled "Processes for Engineering a System." Its purpose was: "to provide an integrated set of fundamental processes to aid a developer in the engineering or re-engineering of a system." [17].
After a trial period that began in 1994, the IEEE 1220 standard titled "Application and Management of the Systems Engineering" was published in 1998. Since it is intended as a set of technical activities and engineering data activities it provided the next-level-of-detail description of the systems engineering processes. In 2006 it became ISO/IEC 26702 and according to IEEE refers to "The interdisciplinary tasks, which are required throughout a system's life cycle to transform customer needs, requirements, and constraints into a system solution, are defined. In addition, the requirements for the systems engineering process and its application throughout the product life cycle are specified. The focus of this standard is on engineering activities necessary to guide product development while ensuring that the product is properly designed to make it affordable to produce, own, operate, maintain, and eventually to dispose of, without undue risk to health or the environment." [18].

The intent of the EIA 632 was to enable an enterprise to strengthen its competitiveness in global markets by engineering and producing quality systems, and by delivering its products on time at an affordable price or cost. The focus then was on conceptualizing, creating, and realizing a system including its constituent products. It should be noted that the EIA 632 was prepared by both the Electronic Industries Alliance (EIA) and the International Council on Systems Engineering (INCOSE), the latter being set-up 5 years earlier. Co-development is therefore applicable also to SE standards and not just to the products or services themselves.

Just under a decade later the International Organization for Standardization (ISO) along with the International ElectroTechnical Commission (IEC) jointly developed ISO/IEC 15288:2002. ISO/IEC 15288 was an effort to create an international system life-cycle standard that was initiated by the same group that created the ISO software life-cycle standard, IEEE/EIA 12207, in 1997. The processes specified in the ISO/IEC 15288 cover the entire acquisition, program management and technical development extent and establish "a common framework from describing the lifecycle of systems created by humans." This standard was revised in early 2008 as part of a harmonization effort to align Systems Engineering and Software Engineering processes. It is now in version ISO/IEC/IEEE 15288:2015. In 2010, the same joint commission of ISO/IEC/JTC1 developed, ISO/IEC 24748 \& ISO/IEC 24765 to provide an SE vocabulary and explain lifecycle management. In 2010 ISO/IEC 24748-1 was published in 4 parts each acting as a guide to the application of processes explained in other SE standards. The ISO/IEC/IEEE 29148:2011 standard contains provisions for the processes and products related to the engineering of requirements for systems and software products and services throughout the life cycle. It can also be applied to enabling systems [12].

Although considerable effort has been dedicated to developing harmonised standards there are still significant challenges [19]. While SE standards have benefited from their late appearance co-existence and conflicts with product standards make it difficult for project managers and project teams to implement efficient project management in 
compliance to SE practises [15], [20], [21]. Indeed, product design still heavily relies on product standards. At the same time while SE standards are being rolled-out and recognised the adaptation of company practices and policies at every revision of a SE standard is not easy. This hinders companies in establishing their own stable SE policies and processes and applying them effectively [22]. The approach promoted so far is to allow companies to tailor the SE processes described in the chosen standards rather than dictate a complete, no compromise, and adoption of one specific standard.

Tailoring is advised when organizations deal with complex products although there is no reason why it can't be applied also to simple systems. In general tailoring will involve tuning and pruning those processes that affect all the life cycle including product development. Enterprises will also tailor when they cannot get what they want or need from a preferred SE standard [23]. Enterprises are usually less willing to change their organizational processes and project specific issues tend to be tackled at a technical process level.

With the introduction of the ISO/IEC 15288 in 2002 SE was formally recognized as a preferred mechanism to establish an agreement for the creation of products and services to be traded between two or more organizationsthe supplier(s) and the acquirer(s). An additional outcome was the issuing of SE guidelines, handbooks and frameworks to sustain the standard. It should also be said that it continues to evolve and grow [24]. Two other SE standards namely ISO/IEC 15939:2007 (system measurement) and ISO/IEC 26702 (SE management), further support the dissemination of a SE approach and culture.

In the first instance the standard identifies a process that supports defining a suitable set of measures that address specific information needs [18]. In its latest form (2017) it provides an elaboration of the measurement process from ISO/IEC/IEEE 15288 and ISO/IEC 12207. The measurement process is applicable to system and software engineering and management disciplines.

In the second instance the standard focuses on engineering activities necessary to guide product development, while ensuring that the product is properly designed to make it affordable to produce, own, operate, maintain and eventually dispose of without undue risk to health or the environment. It focused on the application and management of the systems engineering process: in 2016 it was replaced by part 4 of standard ISO/IEC 24748 [18].

One other important standard correlated to 15288 is ISO/IEC/IEEE 15289-2015 that focuses on life-cycle information items i.e. documentation.

SE standards have evolved intensely over the last 15 years, but it is the ISO/IEC/IEEE 15288 that appears to be taking the stage. The authors believe that this is because of:

- Its connections with many other correlated standards that help package the whole idea of SE across industries;

- It is INCOSE sponsored;

- Its popularity, that is increasing;
- Compatibility to ISO 9001 and Quality Management.

The table below (table 1) classifies and lists the SE standards according to their field of application followed by (figure 1) which illustrates the SE standards along with their past, present and future.

TABLE 1: CLASSIFICATION OF SYSTEMS ENGINEERING ISO STANDARDS WITH THEIR FIELDS OF APPLICATION

\begin{tabular}{|c|c|c|}
\hline Life Cycle processes & $\begin{array}{c}\text { Vocabulary } \\
\text { \& documentation }\end{array}$ & $\begin{array}{l}\text { Management } \\
\text { Processes }\end{array}$ \\
\hline $\begin{array}{l}\text { ISO/IEC } 15289 \\
\text { ISO/IEC } 12207 \\
\text { ISO/IEC } 15504\end{array}$ & $\begin{array}{l}\text { ISO } 24748-1 \\
\text { ISO } 24765 \\
\text { ISO/IEC } 15289\end{array}$ & ISO/IEC 15939 \\
\hline $\begin{array}{c}\text { Quality } \\
\text { Management } \\
\text { Processes }\end{array}$ & $\begin{array}{c}\text { Requirements } \\
\text { Management }\end{array}$ & $\begin{array}{l}\text { Industry or SE } \\
\text { related standards } \\
\text { (examples) }\end{array}$ \\
\hline $\begin{array}{l}\text { ISO } 9001 \\
\text { ISO } 9000-3 \\
\text { ISO } 13485\end{array}$ & $\begin{array}{l}\text { ISO/IEC } 29148 \\
\text { ISO/IEC } 25010 \\
\text { ISO/IEC } 26702 \\
\text { ISO/IEC } 25030 \\
\text { ISO/IEC } 24766\end{array}$ & $\begin{array}{l}\text { Medical and non: } \\
\text { ISO 14971, } \\
\text { ISO 62304, } \\
\text { ISO 90003 } \\
\text { IEC } 61508 \\
\text { ISO } 62366 \\
\text { IEC } 60601 \\
\text { ISO } 13485\end{array}$ \\
\hline
\end{tabular}

We will now take a closer look at the ISO/IEC/IEEE 15288 and that of ISO/IEC/IEEE 29148 standards.

\section{SYNOPSIS OF ISO/IEC/IEEE 15288 \& ISO/IEC/IEEE 29148}

Like many standards SE norms set-out to tackle unmet market needs/demands since the scope of SE is to find a solution to a business problem, opportunity or idea. Often this is tied to the advancement of society/technology needs/proposals that pose new challenges and/or create a legislative/normative gap that needs to be closed. Moreover, it is now commonplace to see standards starting from a framework and guidance placeholder before taking on a more detailed technical slant. A typical timeframe for the development of a technical standard can range from 24 to 48 months or more [25]. The ISO/IEC/IEEE 15288 and ISO/IEC/IEEE 29148 represent two good examples of this journey.

The ISO/IEC/IEEE 15288 standard is the culmination of a cross-industry and cross-standard SE journey that started almost fifty years ago in the military sector with MIL-STD499 (1969). A journey that is far from finished, in fact its application has just started for several industries including medical. Figure 1 shows how things have unfolded over the last 50 years without any sign of slowing down. Indeed, these SE forces have provided an opportunity space for the improved development, deployment and retirement of systems together with a need for relevant and better standards. In the specific case of the ISO/IEC/IEEE 15288 standard it:

- Sets a common framework of processes and descriptions for explaining the life cycle of systems created by humans and defines a set of processes and associated terminology from an engineering viewpoint; 
- Shows that these processes can be applied at any level in the hierarchy of a system's structure;

- Provides processes that support the definition, control and improvement of the system life cycle processes used within an organization or a project;

- Provides a defined set of processes to facilitate communication among acquirers, suppliers and other stake holders in the lifecycle of a system;

- Can be applied to one-of-a-kind systems, mass-produced systems and customized, adaptable systems;

- Accommodates and encompasses other standards, practises and disciplines under one common roof for the benefit of the systems' development team.

The ISO/IEC 15288 was introduced in 2002 to explain processes related to systems engineering: it has strong links to SW standard ISO 12207. It was then updated to ISO/IEC 15288:2008 having been widely used also by the defence sector and their supporting organizations. The redefined versions of this standard, ISO 15288.1 and ISO 15288.2, were published in 2014 for the application of ISO/IEC/IEEE 15288 processes for defence. The processes in this standard are divided into 4 categories which are described as the system lifecycle processes namely: Agreement processes, Organizational project-enabling processes, Technical management processes and Technical processes. In the 2008 version of the ISO/IEC/IEEE 15288 there was a total of 23 processes. This standard was again updated in 2015 and is the current SE standard. In this 2015 version the original 23 processes have been extended to 30 processes which have 181 outcomes derived from 403 activities. The system life cycle processes in this standard are described in relation to a system that is composed of a set of interacting system elements, each of which is implemented to fulfil its respective specified requirements. In this way it standardizes the implementation of the relevant processes and clearly explains each stage with relation to its type of implementation. To achieve the purposes and outcomes of a life cycle model, modified or new life cycle processes are defined because of successful implementation of tailoring processes. The same life cycle stages mentioned in the ISO/IEC/IEEE 15288 standard are reported and explained in ISO/IEC/IEEE 24748 i.e. Concept, development, production, use/support and disposal. The ISO/IEC/IEEE 15288 standard is mostly being implemented in defence/aerospace organizations and, in general, in complex products [26]. On a concluding note, another vital element of the ISO/IEC/IEEE 15288 is that it is a part of an integrated set of standards (under the joint commission of ISO/IEC/JC-1/SC7) thus bringing together other standards (see table 1) in use for Systems Engineering. In addition, the ISO/IEC TR 24748-2, which was published in 2011, serves as a guide for the application of processes explained in ISO/IEC 15288:2008.

In 1998 the IEEE 830 standard was released and was titled 'Recommended Practice for Software Requirements Specifications'. It described the content and qualities of a good software requirements specification (SRS) and presented several sample SRS outlines. Similarly, in 1997 the IEEE/EIA 12207 standard provided a common framework tackling software life cycle processes. Both the IEEE 830-1998 and IEEE/EIA 12207 both placed requirements on documents describing software requirements. Annex B of IEEE 830 explained the relationship between the two sets of requirements for those who wanted to produce documents that simultaneously complied with both standards. In 2011 the ISO/IEC/IEEE 29148 was issued to:

- provide a unified treatment of the processes and products involved in engineering requirements throughout the life cycle of systems and software.

- harmonize IEEE 830, SWEBOK and other standards ${ }^{1}$.

- Provide more emphasis on the characteristics of good requirements, RE activities and processes, operations (and operation context), and different information items (including their structures) such as specification of requirements for stakeholders, systems and software.

- comply with ISO/IEC 15288 and ISO/IEC 12207.

The 29148 is currently under review and will be released in 2018. It too specifies the required processes that are implemented for the engineering of requirements for system and software products (including services) throughout the life cycle of the system including enabling systems [12]. It establishes the construct of a good requirement and provides attributes and characteristics of requirements. Accordingly, the ISO/IEC/IEEE 29148 is concerned with discovering, eliciting, developing, analysing, determining verification methods, validating, communicating, documenting, and managing requirements. It also discusses the iterative and recursive application of requirements processes throughout the life cycle thus aligning it with the INCOSE SE handbook. In this way the 29148 provides guidance in the application of requirements engineering and management processes for requirements-related activities as per ISO/IEC/IEEE 12207 and ISO/IEC/IEEE 15288. So, when the ISO/IEC/IEEE 29148 and ISO/IEC/IEEE 15288 are used together one combines the development and deployment of the system with its enabling systems under one roof.

The principle processes explained in ISO/IEC/IEEE 29148 are the stakeholder requirement definition process and requirement/System requirement analysis process. These two processes result in a baseline set of requirements which flow into the architectural design process where the requirements are allocated, decomposed and traced to system elements/design. For each process, the purpose, activities and outcomes are explained as per the IPO model [12]. The result of requirements engineering is a hierarchy of requirements. This enables an agreed understanding between stakeholders (e.g. acquirers, users, customers, operators, and suppliers) for each requirement. This in turn means that the requirement can be easily validated against the relevant real-world (user) need but also serves as a basis for verifying designs and

${ }^{1}$ ISO/IEC 12207, ISO/IEC/IEEE 15289, ISO/IEC TR 19759, IEEE Std 1233, IEEE Std 1362, ISO/IEC TR 24748-1, ISO/IEC/IEEE 24765 
accepting solutions. In this way the V-model or other preferred SE development model e.g. water-fall, AGILE, is/are satisfied [27].

Key to the requirements engineering processes are 'information items' represented by documents. Typical documents being: Business Requirements (BRS), Stakeholder Requirements Specification (StRS), System Requirements Specification document (SyRS), Software Requirements Specification document (SRS). These information items are explained in ISO/IEC/IEEE 29148 including the relative formats and outlines for each document. The standard also provides a brief explanation of the Concept of Operations (ConOps) and Operational Concepts (OpsCon) documents. The OpsCon document describes what the system will do while the ConOps document explains why the system is needed and what are the strategic and business needs behind the system for the sponsoring enterprise/organization.

The ISO/IEC/IEEE 29148 standard provides also the purpose, scope and effectiveness in terms of requirements planning of the system. These additional information items can be used for the processes explained in ISO/IEC/IEEE 15288. Moreover, the INCOSE handbook applies these processes and gives an elaboration of how they could be used also at an enterprise/organization level.
The INCOSE systems engineering handbook provides an in-depth elaboration of the processes explained in ISO/IEC/IEEE 15288:2015 and aims at ensuring effectiveness across a wide range of applications and industrial sectors. The handbook also elaborates on the practices and activities that are necessary to execute the processes. Along with this elaboration an overview of systems engineering from its origin, evolution to date including its definition journey, is also covered. The handbook besides tackles (at a high level) the tailoring of these processes and, in general, the application of systems engineering thinking. It includes information on how to adapt and scale the SE processes and how to apply them in various applications. Each process is illustrated by an input-processoutput (IPO) diagram which also contemplates the enablers and controls for the processes. From a design team perspective such processes can be the tasks, processes and activities. This renders each IPO diagram very efficient in tailoring as well as providing freedom and effectiveness without necessarily imposing the 'way' as a 'must' [12]. The handbook also adopts the documents and requirements processes explained in ISO/IEC/IEEE 29148:2011 to the requirements discussed in ISO/IEC/IEEE 15288:2015.

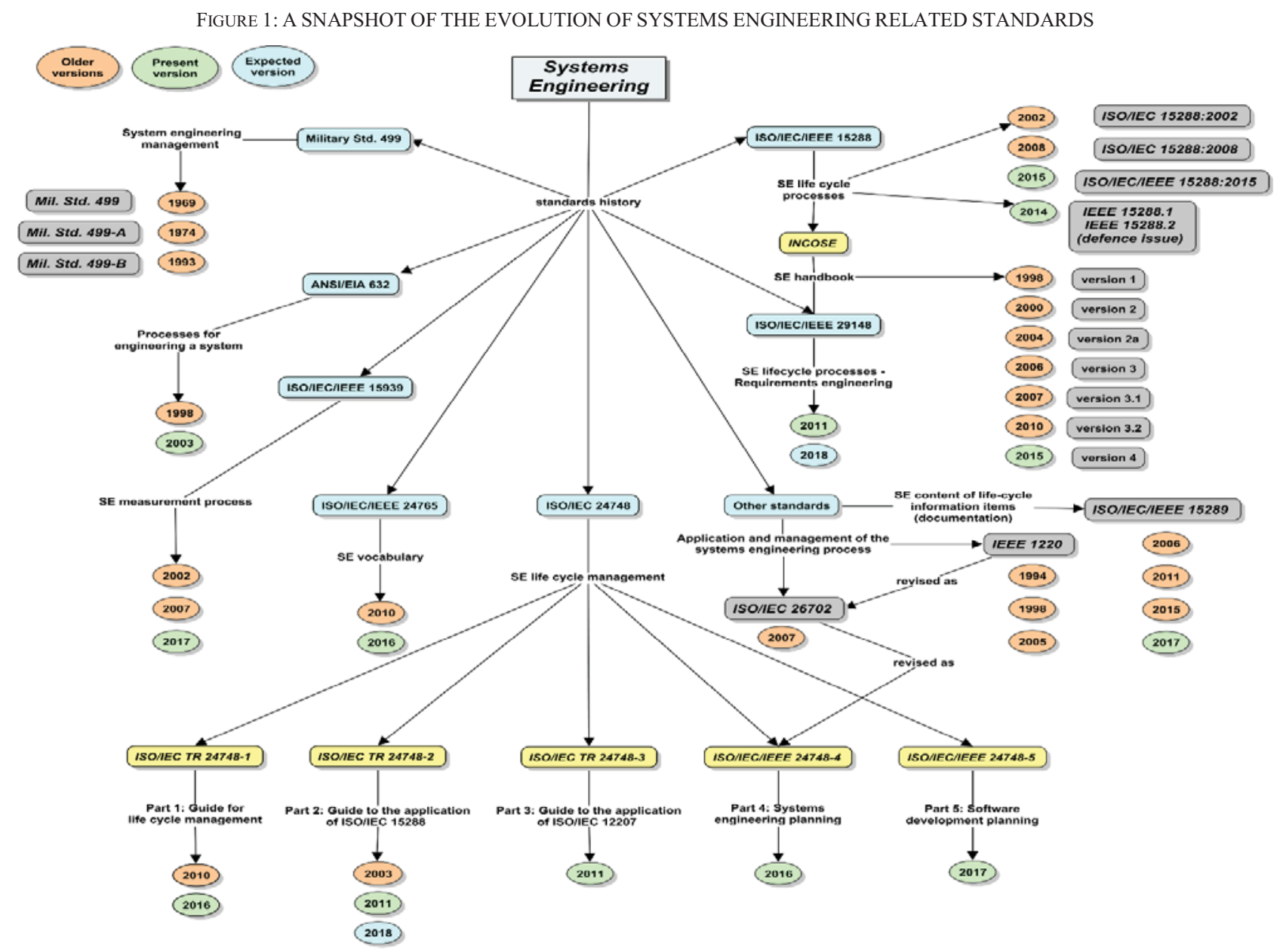




\section{SE TAILORING AND FRAMEWORK}

Although tailoring is usually considered as a lean exercise e.g. deletion of unnecessary or unwarranted process elements, it should be seen also an opportunity to map what is requested, why and what is to be delivered and under what circumstances. The IPO diagram provides perhaps the simplest overview of this reasoning, and in the authors experience is also a very powerful documenting and communication tool between buyer and supplier. In summary the process of tailoring should contemplate at least 4 different questions and most likely in the following order: Why, When, How and Which (element/process).

In the context of 'why' there are numerous drivers (and inhibitors) for change and tailoring, the most common ones are: Efficiency/Effectiveness/Optimisation, Customer satisfaction, Flexibility, Opportunity to learn and improve, anticipate needs and change. An interesting aspect is also exploiting SE standards and documents like the INCOSE handbook to leverage best practises.

Concerning the 'when' this refers to the stage of the system or product life cycle stage and/or PDP, the need behind the request to tailor (see 'why' above) and of change when this need occurs and is clear. Inevitably this entails exploiting an opportunity to satisfy both the buyer and supplier which in turn implies that tailoring must satisfy both parties.

As stated tailoring leverages both relevant standards and the INCOSE handbook i.e. key SE documentation. This implies exploiting specific tools, approaches and methods such as the IPO diagram, PDP, PDM etc. The 'how' is therefore seen here as per the framework shown in figure 2 .

FIGURE 2: TAILORING FRAMEWORK FOR SE

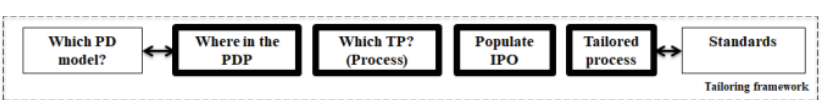

The 'which' question is about selecting which processes to tailor. To this end we leverage especially the technical processes described in the INCOSE handbook because these are the ones closer to the engineering design work typically encountered in high-tech integrators/manufacturers. Clearly the other three categories of process (Organisational, Technical-Managerial and Acquisition) are also relevant but not the scope of the current tailoring investigation and journey to be addressed in the remaining 3 papers mentioned in the conclusions.

\section{CONCLUSIONS}

Key to the deployment and success of SE will be its application and adaptability in time and within the organization and single projects/programs of its sponsors. There is no doubt that the implementation of system life cycle management poses the biggest challenge because the rules and forces declared previously are pushing companies to innovate in a multitude of ways and quicker. ISO/IEC/IEEE 15288 offers a consolidated platform on which companies and industries can provide an orchestrated response to the demands of the marketplace and SE led projects.

A linear and sequential life cycle and development model [28] often needs to work in matrix driven organizational contexts that mingle an 'agile' desire in a simultaneously rigorous and heavily regulated landscape such as in medical. Indeed, the we are seeing the need for 'quick \& dirty' while being accurate and precise. As time progresses we will see the importance of Systems-of-Systems (SoS), Family-ofSystems (FoS), Systems-of-Interest (SoI), etc. emerge from just 'jargon' to being a platform for common thinking and terminology. In other words, it will contemplate the whole, the inception and anything that is in between product development. This is exactly why the ISO/IEC/IEEE 15288 is so important for the future of SE, as well as industry.

The SE journey hasn't been brief and even today certain industries, like defence and aerospace; dominate in terms of experience and return-on-investment in SE development and deployment. The heritage of SE leads to a very intricate landscape of other standards that show a tendency to combine 'mask and maquillage' across disciplines and industries. Evidence that the medical industry has started its journey is limited but nevertheless flagged as a need by the FDA and studied by several authors from around 2004 [29].

In conclusion, given the development of systems thinking and system engineering standards, SE has come to be recognized as a major contributor in proper systems design. Biomedical and healthcare product development can therefore benefit from a SE approach. Firstly, because medical products (systems) are becoming increasingly more complex, and secondly because the development time is being increasingly shortened. This will force earlier definition of the system architecture, relevant requirements freezing and crisper definition of aspects such as risk management, system reliability and safety, essential performance, regulatory requirements, software, human factors etc. In fact, standards such as ISO 14971:2007, ISO 13485:2016, IEC 62366:2015, IEC 62304:2006, IEC 60601:2015, ISO 28000:2007 and UL 2900-1 ${ }^{2}$ [14] are driving organizations to take a deeper look at such aspects.

Organizations, including those in the biomedical and healthcare sectors, that effectively leverage SE standards such as ISO/IEC/IEEE 15288 and ISO/IEC/IEEE 29148 and the INCOSE SE Handbook will be in a much better position to develop safe(r) and effective products once they become common practice [12].

The authors of this paper intend to go forward with the analysis presented in this paper and are developing another 3 papers including a hands-on account of tailoring from the practitioner's perspective based on real industrial case studies in medical.

\footnotetext{
2 ISO 28000, Specification for security management systems for the supply chain. \& UL - 2900-1: Standard for Software Cybersecurity for NetworkConnectable Products, Part 1: General Requirements
} 


\section{REFERENCES}

[1] P. M. Griffin, H. B. Nembhard, C. J. DeFlitch, N. D. Bastian, H. Kang, and D. A. Muñoz, "Healthcare Systems Engineering," SeBok, 2015. [Online]. Available: http://doi.wiley.com/10.1002/9781119174639.

[2] M. S. High and P. E. Rossler, "Engineering Malpractice: Avoiding Liability through Education," Proc. 2006 Midwest Sect. Conf. Am. Soc. Eng. Educ., 2006.

[3] M. Roscini, "Cyber Operations and the Use of Force in International Law,” J. Chem. Inf. Model., vol. 53, no. 9, pp. 1689-1699, 2013.

[4] K. A. Tahboub, "Natural and manmade shared-control systems: An overview," Proc. - IEEE Int. Conf. Robot. Autom., vol. 3, pp. 26552660, 2001.

[5] W. S. Humphrey, Managing the Software Process. Addison-Wesley, 1990.

[6] Y. H. Hwang and J. G. Park, "Approaches and requirements to develop and improve the standard processes for a research and development organization," Syst. Eng., vol. 9, no. 1, pp. 35-44, 2006.

[7] ISO, IEC, and IEEE 15288, "ISO/IEC/IEEE International Standard Systems and software engineering -- System life cycle processes," ISO/IEC/IEEE 15288 First Ed. 2015-05-15, pp. 1-118, 2015.

[8] P. T. Kotler and K. L. Keller, Marketing Management, 15th edition. Pearson, 2016

[9] D. Liu, "Systems Engineering: Design Principles and Models," Syst. Eng., 2015.

[10] A. Kossiakoff, W. N. Sweet, S. J. Seymour, and S. M. Biemer, Systems Engineering Principles and Practice, vol. 102, no. 3. 2011.

[11] "NASA," 2016. [Online]. Available: www.nasa.gov/feature/margarethamilton-apollo-software-engineer-awarded-presidential-medal-offreedom.

[12] D. D. Walden, R. D. Hamelin, G. J. Roedler, K. J. Forsberg, and T. M. Shortell, A guide for system life cycle processes and activities (No. INCOSE-TP-2003-002-004), Fourth., vol. 4. Wiley, 2015.

[13] C. Haskins, K. Forsberg, M. Krueger, D. Walden, and R. D. Hamelin, A guide for system life cycle processes and activities (No. INCOSETP-2003-002-03.2), vol. 3.2. 2010.

[14] "FDA Recognizes UL 2900-1 Cybersecurity Standard for Medical Devices." [Online]. Available: https://www.ul.com/inside-ul/fdarecognizes-ul-2900-1-cybersecurity-standard-for-medical-devices/.

[15] A. Sharon, O. L. De Weck, and D. Dori, "Project management vs. systems engineering management: A practitioners' view on integrating the project and product domains," Syst. Eng., vol. 14, no. 4, pp. 427-440, 2011.

[16] US Military, "Mil-Std 499: MILITARY STANDARD: SYSTEM ENGINEERING MANAGEMENT,” Mil-Std, 1969

[17] E. I. Alliance, "ANSI/EIA/IS 632 Processes for Engineering a System," Gov. Electron. Inf. Technol. Assoc. Eng. Dep., 1998.

[18] ISO/IEC/IEEE FDIS 24748-2, "Systems and software engineering Life cycle management Part 2: Guide to the application of ISO/ IEC 15288," vol. 15288, 2011.

[19] B. Henderson-Sellers, "Standards harmonization: Theory and practice," Softw. Syst. Model., vol. 11, no. 2, pp. 153-161, 2012.

[20] J. Boarder, "Systems Engineering Processes," in Proceedings of the IEEE Annual international, 1995, pp. 293-298.

[21] B. A. Olson, T. A. Mazzuchi, S. Sarkani, and K. Forsberg, "Problem management process, filling the gap in the systems engineering processes between the risk and opportunity processes," Syst. Eng., vol. 15 , no. 3 , pp. $275-286,2012$.

[22] X. Rui, B. Claude, E. Philippe, and Z. Quiang, "Establishing profiles for systems engineering standards: a great help for companies to manage their processes," 2014.

[23] M. Graviss, S. Sarkani, and T. A. Mazzuchi, "TAILORING a Large Organization's SYSTEMS ENGINEERING PROCESS to Meet Project-Specific Needs.," Def. Acquis. Res. J. A Publ. Def. Acquis. Univ., vol. 23, no. 3, pp. 274-297, 2016.
[24] I. C. on S. E. INCOSE, "What is Systems Engineering?," 2015. [Online]. Available: http://www.incose.org/AboutSE/WhatIsSE.

[25] "ISO/IEC Directives, Part 1 Consolidated JTC 1 Supplement 2017 Procedures specific to JTC 1 ISO/IEC Directives, part 1 Consolidated JTC 1 Supplement 2017,” 2016. [Online]. Available: https://www.iso.org/sites/directives/2016/consolidated/index.xhtml\#_i dTextAnchor110.

[26] G. Chang, H. Perng, and J. Juang, "A review of systems engineering standards and processes," J. Biomechatronics Eng., vol. 1, no. 1, pp. 71-85, 2008.

[27] K. Forsberg and H. Mooz, "The relationship of systems engineering to the project cycle," EMJ - Eng. Manag. J., vol. 4, no. 3, pp. 36-43, 1992.

[28] P. Trott and Paul Trott, "Innovation Management and New Product Development," 2005.

[29] G. M. Samaras and R. L. Horst, "A systems engineering perspective on the human-centered design of health information systems," J. Biomed. Inform., vol. 38, no. 1, pp. 61-74, 2005. 